\title{
Communication \\ Characterization of a Novel Mycovirus from the Phytopathogenic Fungus Botryosphaeria dothidea
}

\author{
Yanfen Wang ${ }^{1,+} \oplus$, Hang Zhao ${ }^{1,+}{ }^{,}$, Jiayuan Cao ${ }^{1}$, Xinming Yin ${ }^{1}$, Yashuang Guo ${ }^{1}$, Lihua Guo ${ }^{2}$, Haiyan $W^{3, *}$ \\ and Meng Zhang ${ }^{1,2, *}$
}

check for updates

Citation: Wang, Y.; Zhao, H.; Cao, J.; Yin, X.; Guo, Y.; Guo, L.; Wu, H.; Zhang, M. Characterization of a Novel Mycovirus from the Phytopathogenic Fungus Botryosphaeria dothidea. Viruses 2022, 14, 331. https://doi.org/10.3390/ v14020331

Academic Editors: Ken Komatsu,

Hiromitsu Moriyama and

Islam Hamim

Received: 15 December 2021

Accepted: 2 February 2022

Published: 6 February 2022

Publisher's Note: MDPI stays neutral with regard to jurisdictional claims in published maps and institutional affiliations.

Copyright: (C) 2022 by the authors. Licensee MDPI, Basel, Switzerland. This article is an open access article distributed under the terms and conditions of the Creative Commons Attribution (CC BY) license (https:// creativecommons.org/licenses/by/ $4.0 /)$.
1 School of Plant Protection, Henan Agricultural University, Zhengzhou 450002, China; wyfhist@163.com (Y.W.); zhaohang96@foxmail.com (H.Z.); jiayuan_Cao@126.com (J.C.); xmyin@henau.edu.cn (X.Y.); guoyashuang@henau.edu.cn (Y.G.)

2 State Key Laboratory for Biology of Plant Diseases and Insect Pests, Institute of Plant Protection, Chinese Academy of Agricultural Sciences, Beijing 100193, China; guolihua72@yahoo.com

3 Analytical Instrument Center, Henan Agricultural University, Zhengzhou 450002, China

* Correspondence: ndwhy@126.com (H.W.); zm2006@126.com (M.Z.)

+ These authors contributed equally to this study.

\begin{abstract}
Botryosphaeria dothidea is, globally, one of the most economically important phytopathogenic fungi worldwide, causing the canker and dieback of fruit trees. An increasing number of viruses infecting $B$. dothidea have lately been reported, several of which could confer hypovirulence. In this study, isolated from strain ZM170285-1 of B. dothidea, a novel double-stranded RNA (dsRNA) mycovirus, tentatively named Botryosphaeria dothidea partitivirus 2 (BdPV2), was identified well. The BdPV2 harbored three dsRNA segments (1-3) with lengths of 1751, 1568, and $1198 \mathrm{bp}$, which encoded an RNA-dependent RNA polymerase (RdRp), a capsid protein (CP), and a hypothetical protein of unknown function, respectively. BLASTp searches revealed that the predicted protein sequences of dsRNA1 and dsRNA2 had the highest identities (74.95\% and 61.01\%) with the corresponding dsRNAs of Penicillium stoloniferum virus S (PsV-S), whereas dsRNA3 shared the highest identity (32.95\%) with the dsRNA3 of Aspergillus ochraceous virus 1 (AoV1). Phylogenetic analysis indicated that BdPV2 belonged to the Gammapartitivirus genus and Partitiviridae family. To our knowledge, this is the first report of a Gammapartitivirus in B. dothidea.
\end{abstract}

Keywords: Botryosphaeria dothidea; Botryosphaeria dothidea partitivirus 2 (BdPV2); Gammapartitivirus

\section{Introduction}

Mycoviruses are widely distributed and reported in nearly all major groups of fungi [1-3]. Some mycoviruses can cause the hypovirulence of hosts and, therefore, be used as biocontrol agents for certain fungal diseases [4-6]. Although most mycoviruses had doublestranded RNA (dsRNA) or positive-sense single-stranded RNA (+ssRNA) genomes, several negative-sense single-stranded RNA (-ssRNA) or single-stranded DNA (ssDNA) were described [7-10]. Mycoviruses with dsRNA genomes were classified into seven families: Chrysoviridae, Partitiviridae, Reoviridae, Megabirnaviridae, Totiviridae, Quadriviridae, and Endornaviridae [11]. Members of the Partitiviridae family generally have two or three genome segments (1.4 to $2.4 \mathrm{kbp}$ in length) encoding an RNA-dependent RNA polymerase (RdRp), a capsid protein $(\mathrm{CP})$, and a hypothetical protein with unknown function, respectively [12]. Up to now, five genera in this family have been approved by the International Committee for the Taxonomy of Viruses (ICTV), namely, Alphapartitivirus, Betapartitivirus, Cryspovirus, Deltapartitivirus, and Gammapartitivirus [13]. Recently, however, two additional genera, Epsilsonpartitivirus and Zetapartitivirus, were proposed [14]. Even if most partitiviruses exhibited no obvious effects on their host fungi [12], a few exceptions could interfere with the natural physiology, including morphology, toxin production, and hypovirulence [15-17]. 
Botryosphaeria dothidea (Moug.: Fr.) Ces. and De Not. is a ubiquitous phytopathogen with a broad host range, including pear, poplar, apple, walnut, and jujube trees [18-20], mainly causing fruit rot, branch dieback, and stem warts [21]. Several mycoviruses are present in $B$. dothidea isolates infecting pears and apples but not found in $B$. dothidea isolates infecting walnuts. To date, 11 mycoviruses from $B$. dothidea have been identified belonging to the families Partitiviridae, Totiviridae, Chrysoviridae, Narnaviridae, Botourmiaviridae, and Mitoviridae [6,22-29], the newly proposed family Fusariviridae [25], and an unassigned group [29]. Of these mycoviruses, Botryosphaeria dothidea chrysovirus 1 (BdCV1), Botryosphaeria dothidea RNA virus 1 (BdRV1), Bipolaris maydis botybirnavirus 1 strain BdEW220 (BmRV1-BdEW220) could attenuate the virulence of $B$. dothidea $[6,28,29]$, while the others did not.

In this study, a novel dsRNA virus from strain ZM170285-1 of B. dothidea was identified and characterized. This is the second partitivirus discovered in $B$. dothidea, tentatively named Botryosphaeria dothidea partitivirus 2 (BdPV2). BdPV2 could be transmitted via asexual sporulation at $100 \%$.

\section{Materials and Methods}

\subsection{Fungal Strains and Culture Conditions}

Strains ZM170285-1 and ZM180088 of B. dothidea were isolated from walnut trunks collected in Sanmenxia, Henan province, China. Virus-infected strain ZM170285-1 had an abnormal colony morphology. Protoplast regeneration, hyphal tipping, and ribavirin treatment were used to eliminate the mycoviruses in strain ZM170285-1 [30]. Virus-free strain ZM180088 was used as a control for evaluating biological characteristics. Both strains were cultured on potato dextrose agar (PDA) plates at $25{ }^{\circ} \mathrm{C}$ and stored in sterile $30 \%$ glycerol solution at $4{ }^{\circ} \mathrm{C}$.

\subsection{Extraction and Purification of dsRNA}

Mycelia of the B. dothidea strains were cultured on cellophane membranes laid on PDA plates $\left(9 \mathrm{~cm}\right.$ in diameter) for 5 days at $25^{\circ} \mathrm{C}$. Fresh mycelia were harvested and ground into a fine powder in liquid nitrogen. The extraction and purification of dsRNA were performed as previously described [6]. dsRNA samples were treated with both DNase I and S1 nuclease (TaKaRa, Dalian, China). Purified dsRNA elements were separated in 1.2\% agarose gel at $120 \mathrm{~V}$ and visualized in a UV transilluminator after staining with ethidium bromide (EB).

\section{3. cDNA Synthesis and Cloning}

cDNA synthesis and molecular cloning were performed using random primers $\left(5^{\prime}\right.$ CGATCGATCATGATGCAATGCNNNNNN-3') as previously described [28]. PCR amplicons were ligated into the pMD18-T vector (TaKaRa, Dalian, China) and then transformed into competent Escherichia coli DH5 $\alpha$ cells. Sequences gaps between clones were determined by reverse transcription-PCR (RT-PCR) using specific primers designed on the basis of obtained cDNA sequence. The terminal sequences of each dsRNA were determined [6].

\subsection{Sequence Analysis}

Sequence searches were conducted using the BLASTX or BLASTP program in the NCBI databases (URL). Multiple sequence alignments were performed on the basis of conserved amino acid sequences using MAFFT software [31]. The aligned sequences were shaded using the BoxShade website (https:/ /embnet.vital-it.ch/software/BOX_form.html, accessed on 6 January 2020). ORFs were predicted using ORFfinder (https:/ / www.ncbi. nlm.nih.gov/orffinder/, accessed on 6 January 2020). Phylogenetic trees were constructed using maximum likelihood with a Jones-Taylor-Thornton (JTT) model using MEGA7 software version 7.0 [32]. Bootstrap values were evaluated with 1000 replicates. 


\subsection{Transmission Assay}

Conidia production of the strain ZM170285-1 was induced on PDA plates under alternating light/dark (16 h:8 h) cycles [18]. We individually selected 66 single-conidia isolates to be used for assessing the presence of dsRNAs. Hyphal anastomosis was used to investigate the horizontal transmission of dsRNAs between strains ZM170285-1 and ZM180088. Virus-free (BdPV2 ${ }^{-}$) strain ZM180088 (as the receptor) and virus-infected $\left(\right.$ BdPV2 $^{+}$) strain ZM170285-1 (as the donor) were dual cultured on PDA plates in the dark for 10 days at $25{ }^{\circ} \mathrm{C}$. Ten mycelia agar plugs were obtained from the colony margin of recipients (the farthest site from strain ZM180088) and transferred to a fresh PDA plate for purification with single hyphal tips. The viral transmission was assessed on the basis of RT-PCR amplification and dsRNA extraction.

\subsection{Biological Testing}

Mycelia agar plugs from the colony margin of 3-day-old cultures were inoculated onto fresh PDA medium for subculture. The colony diameters of each strain were measured daily for 3 days, and their mycelia growth rates were calculated. The virulence of the fungal strain was determined according to a previously described method [21]. Briefly, freshly excised mycelia agar plugs of each isolate were inoculated onto four detached 1-year-old stems of walnut trees. Vaccination sites were covered with sterilized moist cotton balls to maintain $90 \%$ relative humidity for 2 days at $30{ }^{\circ} \mathrm{C}$. Lesions induced by the fungus were measured and photographed 10 days post inoculation (dpi). Each treatment described above was performed more than three times.

\section{Results}

\subsection{Genetic Analysis of BdPV2}

Complete dsRNA sequences were obtained by using RT-PCR amplification combined with the RLM-RACE procedure. The full lengths of cDNAs of dsRNAs 1 to 3 are 1751, 1568, and $1198 \mathrm{bp}$, respectively (Figure 1A,B), which were submitted to GenBank under accession numbers MZ044010 to MZ044012. ORFfinder prediction revealed that each of the 3 dsRNAs contained one ORF.

The largest dsRNA1 (49.8\% G+C content) contained one large ORF from nucleotide (nt) 64 to 1683, encoding a protein (P1) of 539 amino acids with a predicted molecular mass (Mr) of $63 \mathrm{kDa}$ (Figure 1B). BLASTp searched of P1 revealed that it shares the highest identity (74.95\%, E-value 0, coverage 100\%) with the RNA-dependent RNA polymerase (RdRp) of Penicillium stoloniferum virus S (PsV-S) and Penicillium brevicompactum partitivirus 1 (PbPV1). P1 also shared similar identities (67.53-74.21\%) to the RdRps of Penicillium digitatum partitivirus 1 (PdPV1), Aspergillus ochraceous virus 1 (AoV1), Verticillium dahliae partitivirus 1 (VdPV1), Aspergillus fumigatus partitivirus 1 (AfuPV-1), and Gremmeniella abietina RNA virus MS1 (GaRV-MS1) (Table 1). Similarly, dsRNA2 (56.57\% G+C content) contained a single ORF from nt 83 to 1390 encoding a 435 aa protein (P2) with a predicted $\mathrm{Mr}$ of $47 \mathrm{kDa}$ (Figure 1B). BLASTp analysis revealed that P2 shared the highest identity $(61.01 \%, E$-value 0, coverage $100 \%)$ with the capsid protein (CP) of PsV-S and high identities (52.41-60.00\%) with the CPs of the other members of the Partitiviridae family (Table 1). The smallest dsRNA3 (48.1\% G+C content) contained a single ORF at nt 257-1000 encoding a 247-aa protein (P3) with a predicted Mr of $28 \mathrm{kDa}$ (Figure 1B). P3 shared the highest identity $\left(32.95 \%, E\right.$-value $1 \times 10^{-28}$, coverage $\left.99 \%\right)$ with a protein of unknown function encoded by dsRNA3 of AoV1. Additionally, P3 shared identities with the putative proteins encoded by dsRNA3 of AfuPV-1 A (37.07\%, E-value $5 \times 10^{-26}$, coverage 79\%) and GaRV-MS1 (31.58\%, $E$-value $1 \times 10^{-20}$, coverage $79 \%$ ) (Table 1$)$. 

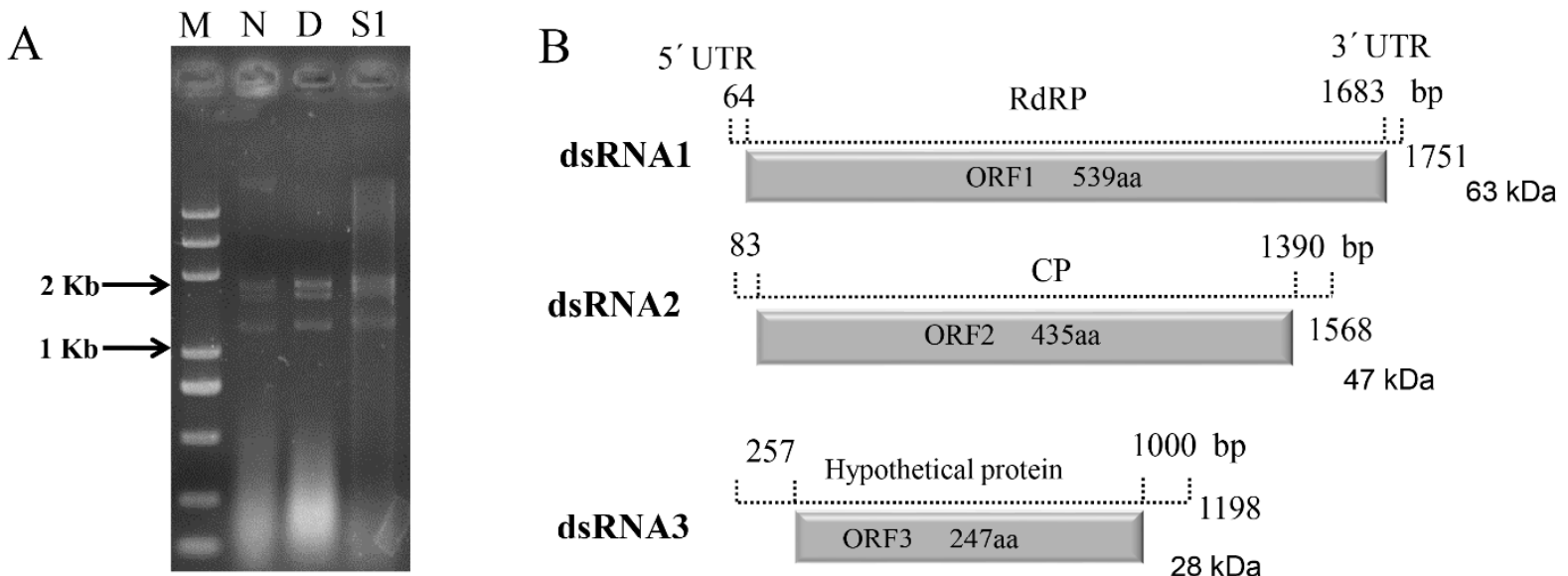

\section{$47 \mathrm{kDa}$}

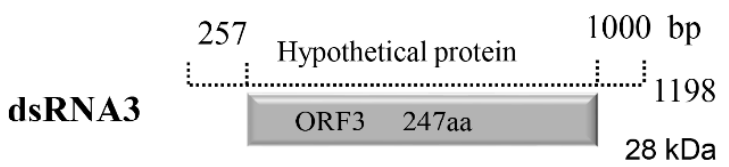

$\mathrm{C}$

\section{5 '- termini}

\section{3'- termini}
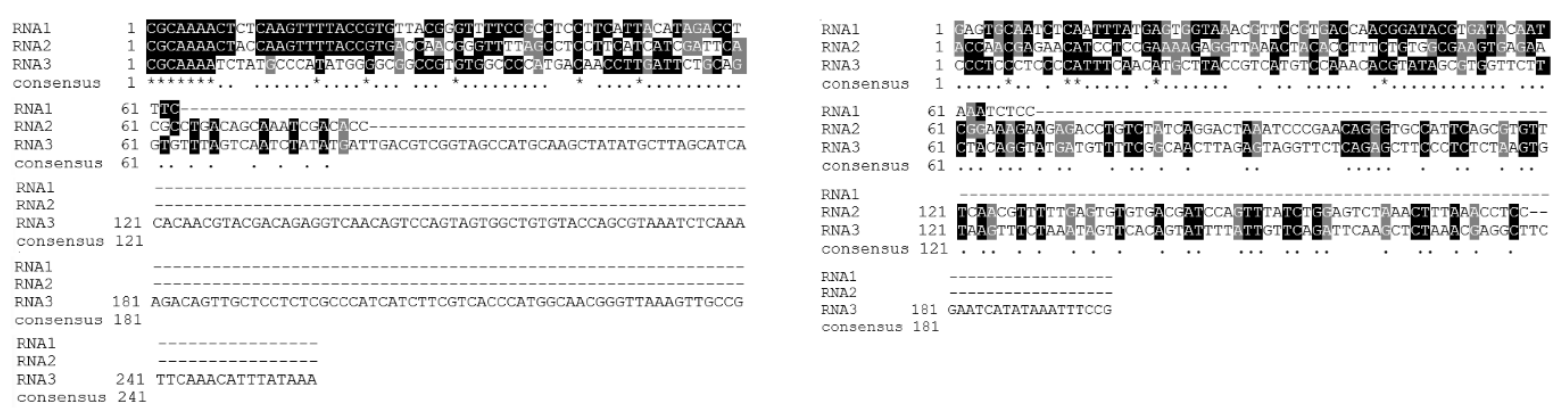

Figure 1. Genomic organization of BdPV2. (A) Lane M, DL5000 DNA marker; Lane N, dsRNA extracted from strain ZM170285-1; Lanes D and S1, dsRNA was treated with DNase I and S1 nuclease. (B) Schematic representation of genomic organization of BdPV2. (C) Multiple sequence alignment of $5^{\prime}$ - and $3^{\prime}$-UTRs of BdPV2. *, conserved amino acid residues.

Table 1. Information of BLASTp search results of Botryosphaeria dothidea partitivirus 2 (BdPV2).

\begin{tabular}{|c|c|c|c|c|c|c|c|}
\hline Virus Name & $\begin{array}{l}\text { Segment } \\
\text { Number }\end{array}$ & ORF (aa) & $\begin{array}{l}\text { Accession } \\
\text { Number }\end{array}$ & $\begin{array}{c}\text { Query } \\
\text { Cover (\%) }\end{array}$ & $\begin{array}{l}\text { Identity } \\
(\%)\end{array}$ & $E$-Values & Reference \\
\hline \multirow{2}{*}{$\begin{array}{l}\text { Penicillium stoloniferum } \\
\text { virus S (PsV-S) }\end{array}$} & 1 & 539 & YP_052856 & 100 & 74.95 & 0 & \multirow{2}{*}{ [33] } \\
\hline & 2 & 434 & YP_052857 & 100 & 61.01 & 0 & \\
\hline \multirow{2}{*}{$\begin{array}{l}\text { Penicillium brevicompactum } \\
\text { partitivirus } 1 \text { (PbPV1) }\end{array}$} & 1 & 539 & AYP71816 & 100 & 74.95 & 0 & \multirow{2}{*}{ [34] } \\
\hline & 2 & 433 & AYP71817 & 100 & 60.00 & 0 & \\
\hline \multirow{2}{*}{$\begin{array}{l}\text { Penicillium digitatum } \\
\text { partitivirus } 1 \text { (PdPV1) }\end{array}$} & 1 & 539 & AZT88594 & 100 & 74.21 & 0 & \multirow{2}{*}{ [35] } \\
\hline & 2 & 434 & AZT88595 & 100 & 59.86 & 0 & \\
\hline \multirow{2}{*}{$\begin{array}{l}\text { Verticillium dahliae } \\
\text { partitivirus } 1 \text { (VdPV1) }\end{array}$} & 1 & 539 & YP_009164038 & 100 & 67.53 & 0 & \multirow{2}{*}{ [36] } \\
\hline & 2 & 436 & YP_009164039 & 99 & 56.68 & $6 \times 10^{-168}$ & \\
\hline \multirow{3}{*}{$\begin{array}{l}\text { Aspergillus ochraceous virus } \\
11 \text { (AoV1) }\end{array}$} & 1 & 539 & YP_009665972 & 100 & 72.91 & 0 & \multirow{3}{*}{ [37] } \\
\hline & 2 & 433 & AYP71819 & 100 & 57.93 & $2 \times 10^{-160}$ & \\
\hline & 3 & 293 & AYP71820 & 99 & 32.95 & $1 \times 10^{-28}$ & \\
\hline \multirow{3}{*}{$\begin{array}{l}\text { Aspergillus fumigatus } \\
\text { partitivirus } 1 \text { (AfuPV-1) } \\
\text { AfuPV-1 A dsRNA3 }\end{array}$} & 1 & 547 & CAY25801 & 100 & 67.53 & 0 & \multirow{2}{*}{ [38] } \\
\hline & 2 & 368 & CAZ61323 & 100 & 55.63 & $5 \times 10^{-170}$ & \\
\hline & 3 & 258 & CAA7351346 & 79 & 37.07 & $5 \times 10^{-26}$ & [39] \\
\hline \multirow{3}{*}{$\begin{array}{l}\text { Gremmeniella abietina RNA } \\
\text { virus MS1 (GaRV-MS1) }\end{array}$} & 1 & 539 & AII16004 & 99 & 70.87 & 0 & \multirow{3}{*}{ [40] } \\
\hline & 2 & 443 & AII16002 & 99 & 52.41 & $3 \times 10^{-155}$ & \\
\hline & 3 & 237 & NP_659029 & 79 & 31.58 & $1 \times 10^{-20}$ & \\
\hline
\end{tabular}


The $5^{\prime}$-untranslated regions (UTRs) of the plus strands of segments dsRNAs 1 to 3 are, respectively, 63, 82, and 256 bp long and share conserved nucleotides (CGCAAA) (Figure 1C). The corresponding 3'-UTRs are 68, 178, and $198 \mathrm{bp}$ long, respectively, and share little sequence conservation (Figure 1C). According to the ICTV, the sequence identity of $\mathrm{CP} \leq 80 \%$ and $\mathrm{RdRp} \leq 90 \%$ are required to define a new species in the Gammapartitivirus genus [11]. Thus, results indicated that dsRNAs 1 to 3 represent the genomic components of a novel virus tentatively named Botryosphaeria dothidea partitivirus 2 (BdPV2), belonging to Gammapartitivirus within the Partitiviridae family.

\subsection{Phylogenetic Analysis of BdPV2}

Phylogenetic trees were established on the basis of amino acid sequences of RdRp and CP from BdPV2 and those of partitiviruses selected from all genera (including newly proposed ones) of the Partitiviridae family, respectively. Results showed that BdPV2 and related partitiviruses (PsV-S, PdPV1, PbPV1, AoV1, and AfuPV-1) were clustered into the Gammapartitivirus cluster (Figure 2A,B). Multiple sequence alignment based on the amino acid sequence of the encoded RdRp revealed six conserved motifs III-VIII in BdPV2 within members of the Partitiviridae family (Figure 2C).

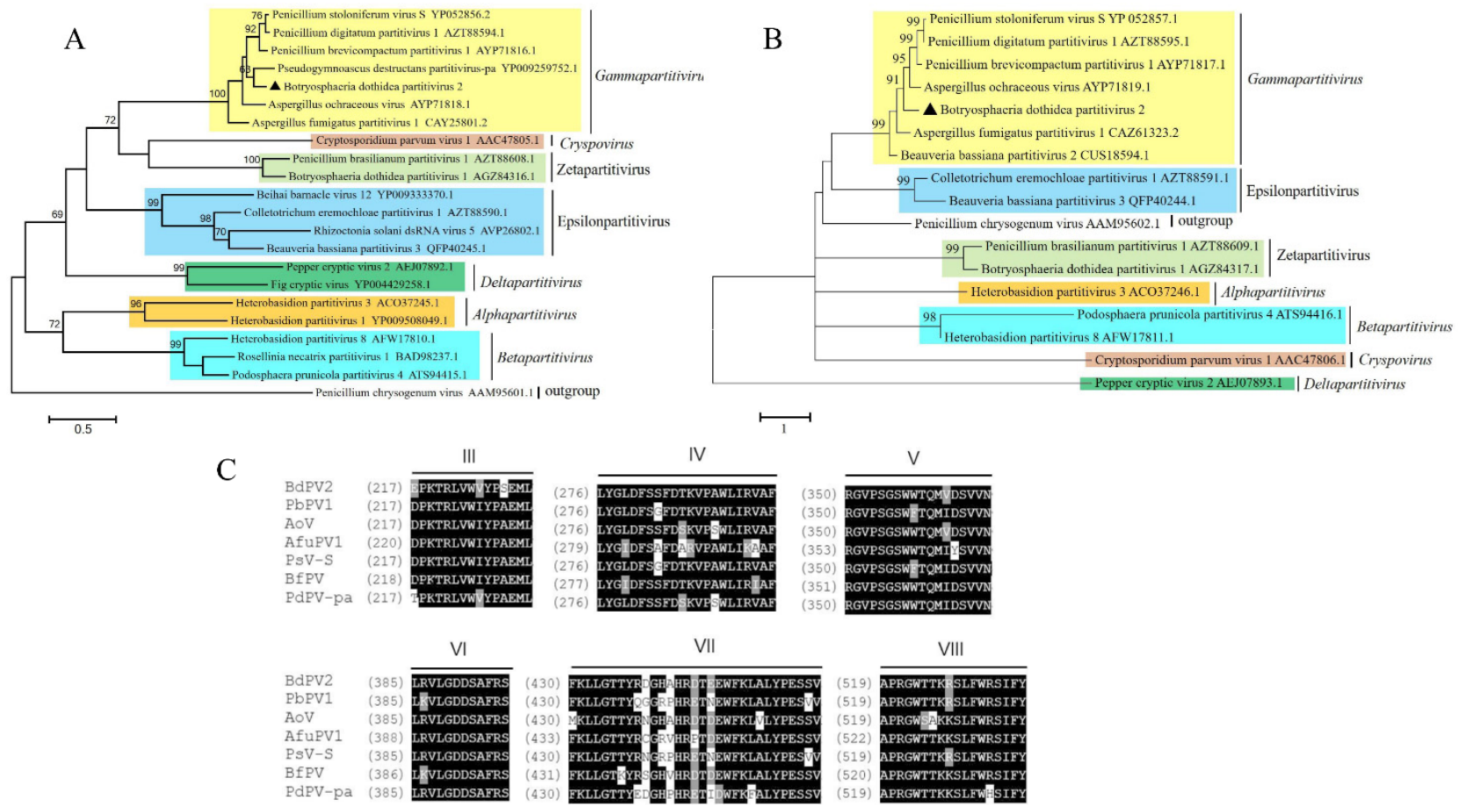

Figure 2. Phylogenetic analysis of BdPV2. Maximum-likelihood (ML) phylogenetic analysis based on amino acid sequences of (A) RdRp and (B) CP of BdPV2 and other selected members of seven genera of the Partitiviridae family. Phylogenetic tree was generated using MEGA 7 with 1000 bootstrap replicates. Triangle indicates position of BdPV2. (C) Multiple alignments of amino acid sequences of RdRp motifs of BdPV2 and other selected mycoviruses in Partitiviridae family. Six motifs (III-VIII) detected in conserved RdRp sequence. Similar amino acid residues are shaded in black.

\subsection{Transmission Assay of BdPV2}

In total, 66 single-conidia derived from B. dothidea strain ZM170285-1 were all infected with BdPV2. To evaluate whether BdPV2 can be horizontally transmitted between B. dothidea strains, strain ZM170285-1 (BdPV2-infected, BdPV2 ${ }^{+}$) was dual cultured with strain ZM180088 (BdPV2-free, BdPV2 ${ }^{-}$) on PDA plates. The infection status of receptor strain ZM180088 was assessed by RT-PCR amplification 10 days after dual culture using RNA isolated from mycelia disks excised from the colony margins of the receptor strain 
(the farthest site from strain ZM180088). None of the 10 tested derivative sub-strains was infected with BdPV2, indicating no viral transfer.

\subsection{Effects of BdPV2 on B. dothidea}

To obtain the virus-free BdPV2 isogenic lineage, a variety of methods, including hyphal tip culture, protoplast regeneration, and ribavirin treatment, have been tried, but all failed. Meanwhile, to check the effects of BdPV2 on the biological characteristics of $B$. dothidea, the colony morphology and growth rate of strains ZM170285-1 (BdPV2 ${ }^{+}$) and ZM180088 (BdPV2 ${ }^{-}$) were compared. Strain ZM180088 grew rapidly with a growth rate of $3.0 \mathrm{~cm} / \mathrm{d}$ and developed dense mycelia, while strain ZM170285-1 grew slowly with a growth rate of $1.8 \mathrm{~cm} / \mathrm{d}$ and exhibited abnormal morphologies with irregular colony margins (Figure 3A). As inoculated on branches, strain ZM170285-1 induced small necrotic lesions (approximately $1.8 \mathrm{~cm}$ ) around the inoculation point of the walnuts, while strain ZM180088 induced obviously long (approximately $8 \mathrm{~cm}$ ) and typical brown necrosis lesions (Figure 3B). These results indicate that strain ZM170285-1 is weakly virulent.

A
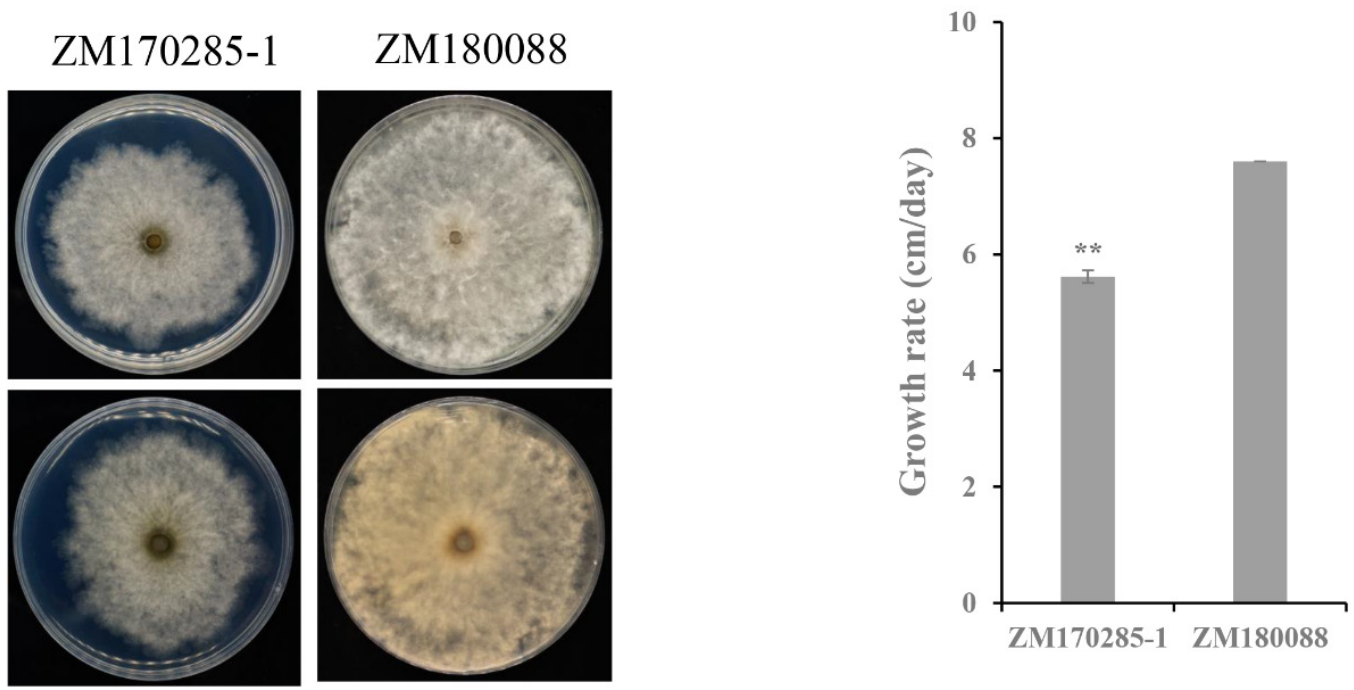

B
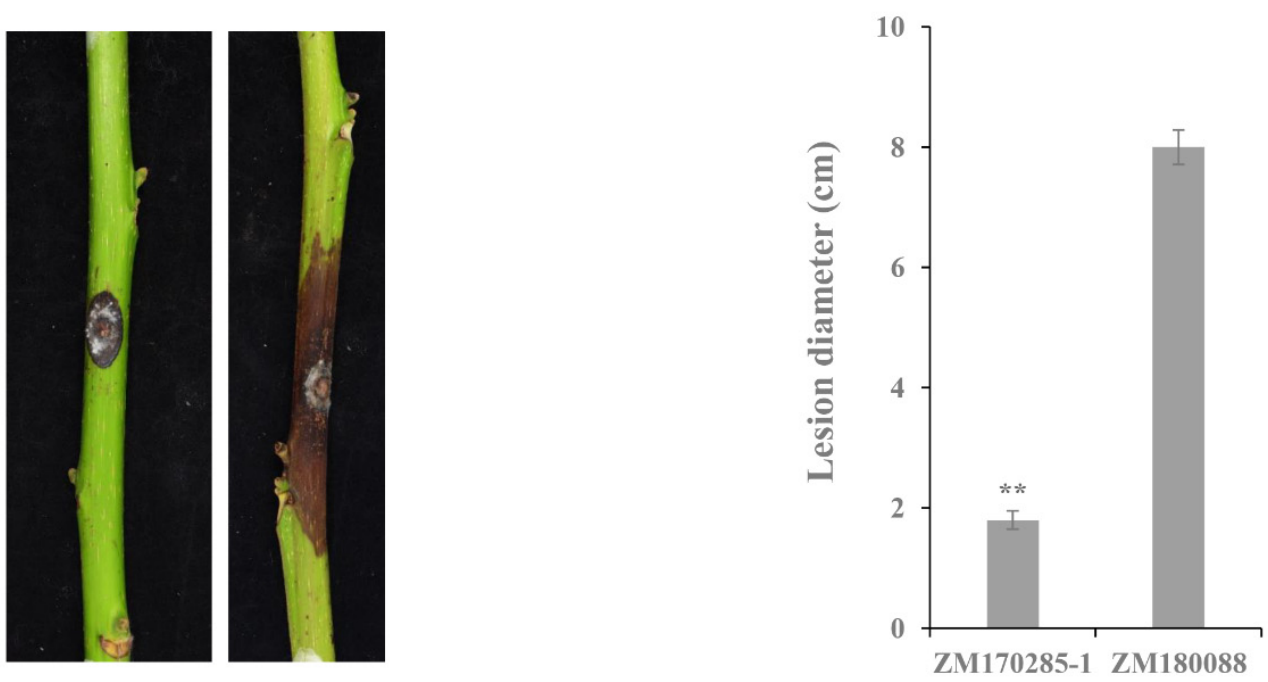

Figure 3. Biological characteristic comparison between strains ZM170285-1 and ZM180088. (A) Colony morphology and growth rates of strains ZM170285-1 and ZM180088 grown at $25{ }^{\circ} \mathrm{C}$ for 3 days on PDA medium. (B) Pathogenicity assay and lesion diameters of two strains grown on detached walnut stems at 10 days post inoculation at $30{ }^{\circ} \mathrm{C}$, and approximately $90 \%$ relative humidity. **, indicates a significant difference $(p<0.01)$ between strains ZM170285-1 and ZM180088. 


\section{Discussion}

To date, only a few $B$. dothidea isolates from pear or apple have been reported to possess several mycoviruses [27]. However, there is no research on mycoviruses of B. dothidea strains that infected any other fruit trees. In this study, from B. dothidea strain ZM170285-1 (causing walnut dieback), we isolated and characterized novel mycovirus BdPV2 with three dsRNA segments that encodes an RdRp, a CP, and a hypothetical protein of unknown function. This genomic organization of BdPV2 is in full accordance with mycoviruses AoV1, AfuPV-1 A, and GaRV-MS1 [37,39,40], but quite different from PsV-S, PbPV1, PdPV1, and VdPV1 [33-36], which all have just two dsRNA segments encoding an RdRp and a CP. The $5^{\prime}$-UTRs of dsRNAs 1 to 3 of BdPV2 showed a conserved nucleotide motif (CGCAAA), which is a feature of multi-component RNA viruses [12].

On the basis of phylogenetic analysis, known viruses of the Gammapartitivirus genus were separated into several different clades (Figure 3A,B). BdPV2 was more closely related to AoV1 that could infect the plant pathogenic fungus Aspergillus ochraceus [37]. The amino acid sequences encoded by dsRNAs 1 to 3 of BdPV2 shared $72.9 \%, 57.9 \%$, and $32.9 \%$ identities, respectively, with the corresponding dsRNAs of AoV1. The $5^{\prime}$-terminal sequences of dsRNAs 1 to 3 shared $59.7 \%, 51.1 \%$, and $42.6 \%$ identities, respectively, with the corresponding sequences of AoV1 [37]. The conserved regions near the $5^{\prime}$ termini of viral genomic RNA may be involved in viral packaging and/or replication [41].

Most mycoviruses can be transmitted vertically via fungal spores or horizontally via hyphal anastomosis [10]. In nature, vegetative incompatibility reduces or abolishes mycoviral transmission between fungal strains, whereas vegetatively compatible fungi can easily transmit and exchange mycoviruses [42]. Both SsHADV-1 and SsPV1 were reported to be able to transmit between different vegetatively compatible individuals $[5,43]$. However, Wu et al. (2017) discovered that SsMYRV4 could not only be transmitted among vegetatively incompatible groups but also promote the transmission of other viruses [44]. In this study, BdPV2 could not be transmitted to the B. dothidea strain ZM180088 after dual culture, which was similar to BdPV1 [6]. Another report found that BmBRV1-BdEW220 could be transmitted among different strains derived from a single conidium but not transferred to strains of different origins [28]. Therefore, further studies are required to assess if BdPV2 can be transferred to strains from similar origins. As anticipated for partitiviruses [45], BdPV2 was easily transmissible via asexual conidia. To obtain the virus-free ZM170285-1 isogenic lineage, we attempted to eliminate BdPV2 dsRNA from infected cultures failed, including hyphal tip culture, protoplast regeneration, and ribavirin treatment, suggesting that this virus may have evolved effective strategies in $B$. dothidea.

Partitiviruses generally cause latent infections and seldom alter the biological traits of their fungal hosts [16,17]. Nevertheless, some partitiviruses could cause abnormal phenotypes or reduced virulence of their hosts. For instance, SsPV1 not only caused the slow growth and abnormal colony morphology of S. sclerotiorum but also reduced its virulence and sclerotium production [43]. AfuPV1 infection elicited the abnormal colony phenotype, slow growth, and lighter pigmentation [38]. In the current study, there were significant differences between the growth rate and virulence of the BdPV2-infected strain ZM170258-1 and the BdPV2-free strain ZM180088. However, due to the absence of virusfree isogenic lineage, it is difficult to obtain details of the interaction between BdPV2 and B. dothidea. Therefore, it is not clear whether the morphological and weak pathogenicity of B. dothidea strain ZM170285-1 is associated with BdPV2 infection, and further investigation is needed to explore its potential for use in the biological control of diseases caused by B. dothidea.

Author Contributions: M.Z. and H.W. conceived and designed the experiments. Y.W., H.Z. and J.C. performed the experiments. Y.W., H.Z. and Y.G. analyzed the data. Y.W. and H.Z. wrote the paper. L.G. and X.Y. revised the paper. All authors have read and agreed to the published version of the manuscript. 
Funding: This study was financially supported by the open fund of State Key Laboratory for Biology of Plant Diseases and Insect Pests (SKLOF202103) and the China Agriculture Research System of MOF and MARA (CARS-27).

Institutional Review Board Statement: Not applicable.

Informed Consent Statement: Not applicable.

Data Availability Statement: Not applicable.

Conflicts of Interest: The authors declare no conflict of interest.

\section{References}

1. Ghabrial, S.A.; Caston, J.R.; Jiang, D.; Nibert, M.L.; Suzuki, N. 50-plus years of fungal viruses. Virology 2015, 479, 356-368. [CrossRef] [PubMed]

2. Ghabrial, S.A.; Suzuki, N. Viruses of plant pathogenic fungi. Annu. Rev. Phytopathol. 2009, 47, 353-384. [CrossRef] [PubMed]

3. Pearson, M.N.; Beever, R.E.; Boine, B.; Arthur, K. Mycoviruses of filamentous fungi and their relevance to plant pathology. Mol. Plant Pathol. 2009, 10, 115-128. [CrossRef] [PubMed]

4. Wei, C.Z.; Saki, H.; Iwanami, T.; Matsumoto, N.; Ohtsu, Y. Molecular characterization of dsRNA segments 2 and 5 and electron microscopy of a novel reovirus from a hypovirulent isolate, W370, of the plant pathogen Rosellinia necatrix. J. Gen. Virol. 2003, 84, 2431-2437. [CrossRef]

5. Yu, X.; Li, B.; Jiang, D.; Ghabrial, S.A.; Li, G.; Peng, Y.; Xie, J.; Huang, J.; Yi, X. A geminivirus-related DNA mycovirus that confers hypovirulence to a plant pathogenic fungus. Proc. Natl. Acad. Sci. USA 2010, 107, 8387-8392. [CrossRef]

6. Wang, L.P.; Jiang, J.J.; Wang, Y.F.; Hong, N.; Zhang, F.P.; Xu, W.X.; Wang, G.P. Hypovirulence of the phytopathogenic fungus Botryosphaeria dothidea: Association with a coinfecting chrysovirus and a partitivirus. J. Virol. 2014, 88, 7517-7527. [CrossRef]

7. Donaire, L.; Pagán, I.; Ayllón, M.A. Characterization of Botrytis cinerea negative-stranded RNA virus 1, a new mycovirus related to plant viruses, and a reconstruction of host pattern evolution in negative-sense ssRNA viruses. Virology 2016, 499, 212-218. [CrossRef]

8. $\quad \mathrm{Mu}$, F.; Xie, J.T.; Cheng, S.F.; You, M.P.; Barbetti, M.J.; Jia, J.C.; Wang, Q.Q.; Cheng, J.S.; Fu, Y.P.; Chen, T.; et al. Virome characterization of a collection of Sclerotinia sclerotiorum from Australia. Front. Microbiol. 2018, 8, 2540. [CrossRef]

9. Wang, L.; He, H.; Wang, S.C.; Chen, X.G.; Qiu, D.W.; Kondo, H.; Guo, L.H. Evidence for a novel negative-stranded RNA mycovirus isolated from the plant pathogenic fungus Fusarium graminearum. Virology 2018, 518, 232-240. [CrossRef]

10. Li, H.; Bian, R.; Liu, Q.; Yang, L.; Pang, T.; Salaipeth, L.; Andika, I.B.; Kondo, H.; Sun, L. Identification of a novel hypovirulenceinducing hypovirus from Alternaria alternata. Front. Microbiol. 2019, 10, 1076. [CrossRef]

11. Jiang, Y.; Wang, J.; Yang, B.; Wang, Q.; Zhou, J.; Yu, W. Molecular characterization of a debilitation-associated partitivirus Infecting the pathogenic fungus aspergillus flavus. Front. Microbiol. 2019, 10, 626. [CrossRef] [PubMed]

12. Nibert, M.L.; Ghabrial, S.A.; Maiss, E.; Lesker, T.; Vainio, E.J.; Jiang, D.; Suzuki, N. Taxonomic reorganization of family Partitiviridae and other recent progress in partitivirus research. Virus Res. 2014, 188, 128-141. [CrossRef] [PubMed]

13. Vainio, E.J.; Chiba, S.; Ghabrial, S.A.; Maiss, E.; Roossinck, M.; Sabanadzovic, S.; Suzuki, N.; Xie, J.T.; Nibert, M.; Consortium, I.R. ICTV virus taxonomy profle: Partitiviridae. J. Gener. Virol. 2018, 99, 17-18. [CrossRef] [PubMed]

14. Shiba, K.; Hatta, C.; Sasai, S.; Tojo, M.; Ohki, S.T.; Mochizuki, T. Genome sequence of a novel partitivirus identified from the oomycete Pythium nunn. Arch. Virol. 2018, 163, 2561-2563. [CrossRef]

15. Wu, L.P.; Du, Y.M.; Xiao, H.; Peng, L.; Li, R. Complete genomic sequence of tea oil camellia deltapartitivirus 1, a novel virus from Camellia oleifera. Arch. Virol. 2020, 165, 227-231. [CrossRef]

16. Zhang, C.J.; Zhou, X.Y.; Zhong, J.; Guo, J.; Yang, X.P.; Zhu, H.J. Complete nucleotide sequence of a novel partitivirus infecting the plant-pathogenic fungus Phomopsis vexans. Arch. Virol. 2021, 166, 291-294. [CrossRef]

17. Nibert, M.L.; Woods, K.M.; Upton, S.J.; Ghabrial, S.A. Cryspovirus: A new genus of protozoan viruses in the family Partitiviridae. Arch. Virol. 2009, 154, 1959-1965. [CrossRef]

18. Zhai, L.F.; Zhang, M.X.; Lv, G.; Chen, X.R.; Jia, N.N.; Hong, N.; Wang, G.P. Biological and molecular characterization of four Botryosphaeria species isolated from pear plants showing stem wart and stem canker in China. Plant Dis. 2014, 98, 716-726. [CrossRef]

19. Ding, Z.; Zhou, T.; Guo, L.Y. Characterization of a novel strain of Botryosphaeria dothidea chrysovirus 1 from the apple white rot pathogen Botryosphaeria dothidea. Arch. Virol. 2017, 162, 2097-2102. [CrossRef]

20. Gusella, G.; Giambra, S.; Conigliaro, G.; Burruano, S.; Polizzi, G. Botryosphaeriaceae species causing canker and dieback of English walnut (Juglans regia) in Italy. For. Pathol. 2021, 51, e12661. [CrossRef]

21. Slippers, B.; Wingfield, M.J. Botryosphaeriaceae as endophytes and latent pathogens of woody plants: Diversity, ecology and impact. Fungal Biol. Rev. 2007, 21, 90-106. [CrossRef]

22. Zhai, L.F.; Hong, N.; Zhang, M.X.; Wang, G.P. Complete dsRNA sequence of a novel victorivirus isolated from the pear stem wart fungus Botryosphaeria dothidea. Arch. Virol. 2015, 160, 613-616. [CrossRef] [PubMed]

23. Yang, M.M.; Zhai, L.F.; Xiao, F.; Guo, Y.; Fu, M.; Hong, N.; Wang, G.P. Characterization of a novel victorivirus isolated from the phytopathogenic fungus Botryosphaeria dothidea. Arch. Virol. 2019, 164, 1609-1617. [CrossRef] [PubMed] 
24. Yang, M.M.; Zhou, X.; Zhai, L.F.; Xiao, F.; Hong, N.; Wang, G.P. Molecular characterization of a novel mycovirus infecting the phytopathogenic fungus Botryosphaeria dothidea. Arch. Virol. 2020, 165, 1667-1670. [CrossRef]

25. Liu, W.; Hai, D.; Mu, F.; Yu, X.; Zhao, Y.; He, B.; Xie, J.; Jiang, D.; Liu, H. Molecular characterization of a novel fusarivirus infecting the plant-pathogenic fungus Botryosphaeria dothidea. Arch. Virol. 2020, 165, 1033-1037. [CrossRef] [PubMed]

26. Liu, H.; Liu, M.; Zhu, H.; Zhong, J.; Liao, X.; Zhou, Q. Molecular characterization of a novel mitovirus from the plant-pathogenic fungus Botryosphaeria dothidea. Arch. Virol. 2020, 166, 633-637. [CrossRef]

27. Wang, H.; Liu, H.; Lu, X.; Wang, Y.; Zhou, Q. A novel mitovirus isolated from the phytopathogenic fungus Botryosphaeria dothidea. Arch. Virol. 2021, 166, 1507-1511. [CrossRef]

28. Zhai, L.F.; Yang, M.M.; Zhang, M.X.; Hong, N.; Wang, G.P. Characterization of a botybirnavirus conferring hypovirulence in the phytopathogenic fungus Botryosphaeria dothidea. Viruses 2019, 11, 266. [CrossRef]

29. Zhai, L.F.; Xiang, J.; Zhang, M.X.; Fu, M.; Yang, Z.K.; Hong, N.; Wang, G.P. Characterization of a novel double-stranded RNA mycovirus conferring hypovirulence from the phytopathogenic fungus Botryosphaeria dothidea. Virology 2016, 493, 75-85. [CrossRef]

30. Chen, Y.; Gai, X.T.; Chen, R.X.; Li, C.X.; Zhao, G.K.; Xia, Z.Y.; Zou, C.M.; Zhong, J. Characterization of three novel betapartitiviruses co-infecting the phytopathogenic fungus Rhizoctonia solani. Virus Res. 2019, 270, 197649. [CrossRef]

31. Katoh, K.; Standley, D.M. MAFFT multiple sequence alignment software version 7: Improvements in performance and usability. Mol. Biol. Evol. 2013, 30, 772-780. [CrossRef]

32. Kumar, S.; Stecher, G.; Tamura, K. MEGA7: Molecular evolutionary genetics analysis version 7.0 for bigger datasets. Mol. Biol. Evol. 2016, 33, 1870-1874. [CrossRef] [PubMed]

33. Kim, J.W.; Kim, S.Y.; Kim, K. Genome organization and expression of the Penicillium stoloniferum virus S. Virus Genes 2003, 27, 249-256. [CrossRef] [PubMed]

34. Nerva, L.; Forgia, M.; Ciuffo, M.; Chitarra, W.; Chiapello, M.; Vallino, M.; Varese, G.C.; Turina, M. The mycovirome of a fungal collection from the sea cucumber Holothuria polii. Virus Res. 2019, 273, 197737. [CrossRef] [PubMed]

35. Gilbert, K.; Holcomb, E.; Allscheid, R.; Carrington, J. Hiding in plain sight: New virus genomes discovered via a systematic analysis of fungal public transcriptomes. PLoS ONE 2019, 14, e0219207. [CrossRef] [PubMed]

36. Canizares, M.; Perez-Artes, E.; García-Pedrajas, N.; Garcia-Pedrajas, M. Characterization of a new partitivirus strain in Verticillium dahliae provides further evidence of the spread of the highly virulent defoliating pathotype through new introductions. Phytopathol. Mediterr. 2015, 54, 516-523.

37. Liu, W.; Duns, G.; Chen, J. Genomic characterization of a novel partitivirus infecting Aspergillus ochraceus. Virus Genes 2008, 37, 322-327. [CrossRef]

38. Bhatti, M.F.; Bignell, E.M.; Coutts, R.H.A. Complete nucleotide sequences of two dsRNAs associated with a new partitivirus infecting Aspergillus fumigatus. Arch. Virol. 2011, 156, 1677-1680. [CrossRef]

39. Filippou, C.; Coutts, R.H.A.; Stevens, D.A.; Sabino, R.; Kotta-Loizou, I. Completion of the sequence of the Aspergillus fumigatus partitivirus 1 genome. Arch. Virol. 2020, 165, 1891-1894. [CrossRef]

40. Botella, L.; Tuomivirta, T.T.; Hantula, J.; Diez, J.J.; Jankovsky, L. The European race of Gremmeniella abietina hosts a single species of Gammapartitivirus showing a global distribution and possible recombinant events in its history. Fungal Biol. 2015, 119, 125-135. [CrossRef]

41. Anzola, J.V.; Xu, Z.K.; Asamizu, T.; Nuss, D.L. Segment-specific inverted repeats found adjacent to conserved terminal sequences in wound tumor virus genome and defective interfering RNAs. Proc. Natl. Acad. Sci. USA 1987, 84, 8301-8305. [CrossRef] [PubMed]

42. Xie, J.T.; Jiang, D.H. New insights into mycoviruses and exploration for the biological control of crop fungal diseases. Annu. Rev. Phytopathol. 2014, 52, 45-68. [CrossRef] [PubMed]

43. Xiao, X.; Cheng, J.; Tang, J.; Fu, Y.; Jiang, D.; Baker, T.S.; Ghabrial, S.A. A novel partitivirus that confers hypovirulence on plant pathogenic fungi. J. Virol. 2014, 88, 10120-10133. [CrossRef] [PubMed]

44. Wu, S.; Cheng, J.S.; Fu, Y.P.; Chen, T.; Jiang, D.H.; Ghabrial, S.A.; Xie, J.T. Virus-mediated suppression of host non-self recognition facilitates horizontal transmission of heterologous viruses. PLoS Pathog. 2017, 13, e1006234. [CrossRef]

45. Vainio, E.J.; Korhonen, K.; Tuomivirta, T.; Hantula, J. A novel putative partitivirus of the saprotrophic fungus Heterobasidion ecrustosum infects pathogenic species of the Heterobasidion annosum complex. Fungal Biol. 2010, 114, 955-965. [CrossRef] 